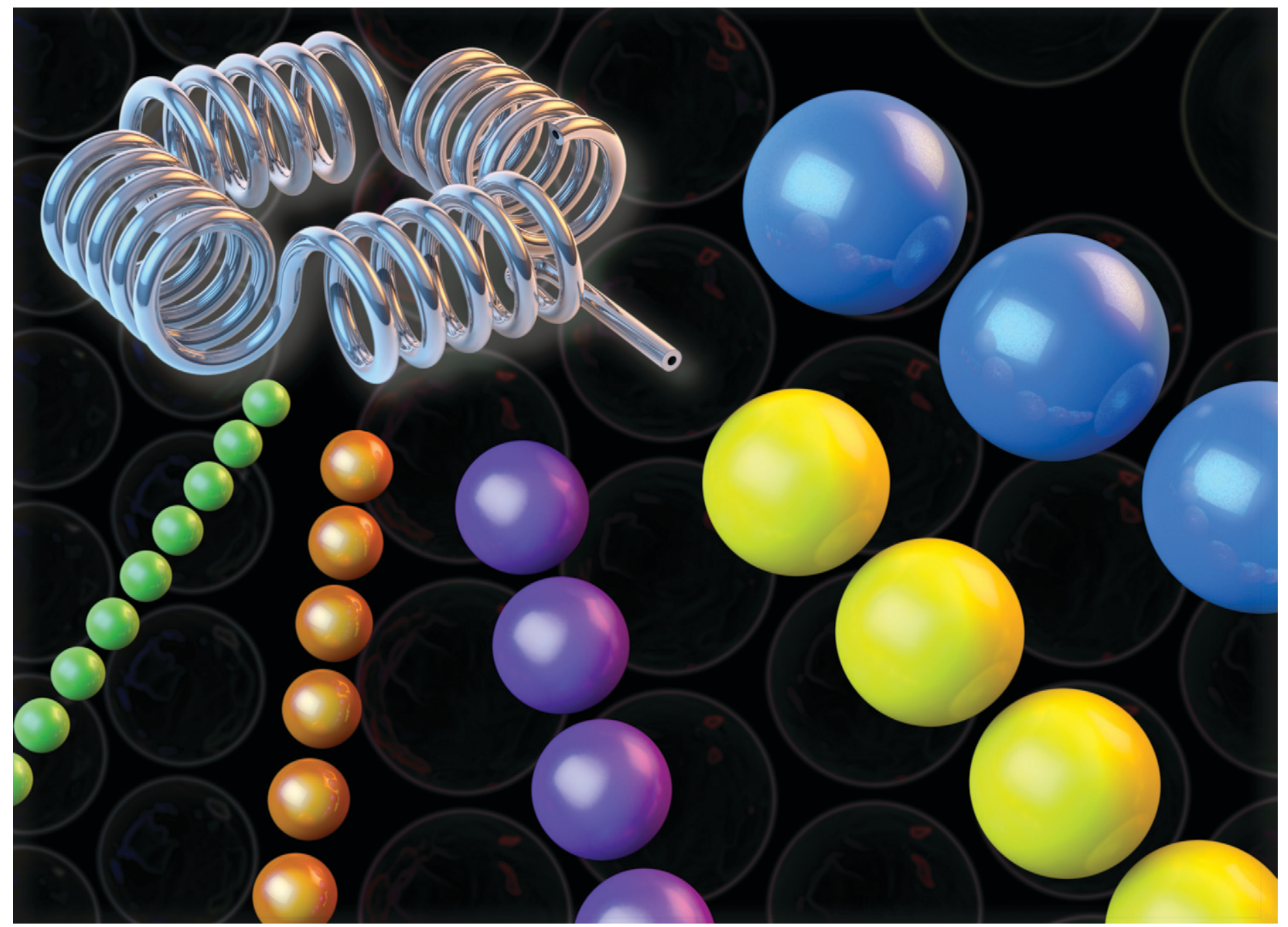

Showcasing research from the Catalysis and Process Integration group led by Dr Laura Torrente-Murciano in the Department of Chemical Engineering and Biotechnology, University of Cambridge.

Continuous synthesis of tuneable sized silver nanoparticles via a tandem seed-mediated method in coiled flow inverter reactors

The continuous synthesis of metal nanoparticles with tuneable sizes in the absence of organic capping ligands is presented. 3D microreactors connected in series enable the separation of the nucleation and growth steps during the synthesis of silver nanoparticles. The coiled flow inverted reactor configuration promotes the rotation of the fluid, limiting the agglomeration of the particles, and leading to narrow size distributions.
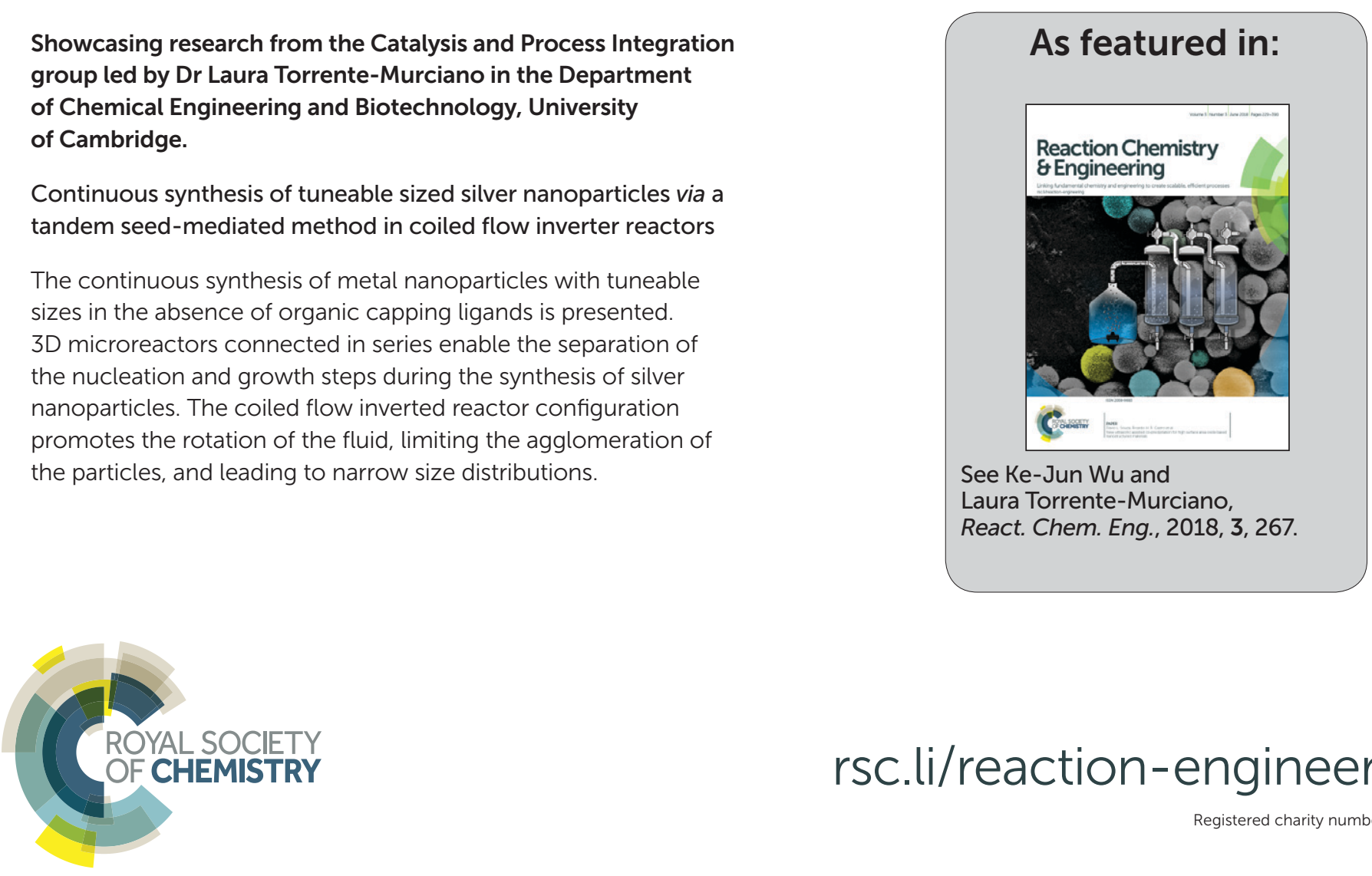
Check for updates

Cite this: React. Chem. Eng., 2018, 3, 267

Received 26th November 2017, Accepted 28th February 2018

DOI: 10.1039/c7re00194k

rsc.li/reaction-engineering

\section{Continuous synthesis of tuneable sized silver nanoparticles via a tandem seed-mediated method in coiled flow inverter reactors}

\author{
Ke-Jun Wu (DD and Laura Torrente-Murciano (D)*
}

\begin{abstract}
Size control of metal nanoparticles is essential to achieve accurate adjustment of their unique chemical and physical properties. In this work, we present a novel approach for the continuous synthesis of silver nanoparticles with tuneable sizes between $5-10 \mathrm{~nm}$ and narrow size distribution $(<20 \%)$ in the absence of steric capping ligands via a seed-mediated method. For this, two flow reactors are connected in series where rapid changes in the chemical environment enable the spatial and temporal separation of the nucleation and growth stages. A novel coiled flow inverter reactor configuration was developed to provide substantial cross sectional Dean mixing, substantially narrowing the residence time distribution under laminar flow. We also demonstrate that careful control of the nature of the reducing agents in each step is essential to avoid secondary nucleation and ensure narrow size distributions. This innovative new capability will not only provide fundamental understanding of the effect of the size of nanoparticles in a number of applications but also enable the deployment of large-scale well-defined nanoparticles for commercial uses.
\end{abstract}

\section{Introduction}

Metal nanoparticles are used for a wide range of applications due to their unique electrical, optical, and magnetic properties as well as the catalytic activity. ${ }^{1-3}$ The ability to achieve size-controlled synthesis of metal nanoparticles is of significant importance to provide an accurate adjustment of the colloidal properties. For instance, the antibacterial activity of silver nanoparticles against $E$. coli and $S$. aureus is known to be closely related to their size ${ }^{4}$ similarly to the catalytic activity of gold nanoparticles for low temperature oxidation..$^{5-7}$ Among many metal nanoparticles, silver nanoparticles have attracted increasing interest in various fields, including medical, food, health care, consumer goods and imaging as a result of their unique optical, catalytic, electronic and antibacterial properties. ${ }^{8}$ In addition, silver nanoparticles are particularly attractive as industrial catalysts due to their relatively low price, approximately $1 / 50$ of the price of gold or platinum and $1 / 25$ of the price of palladium. ${ }^{9}$

Size-controlled silver nanoparticles is usually difficult to achieve in batch synthetic systems due to the simultaneous agglomeration taking place. ${ }^{10}$ Due to this reason, most synthetic procedures include the addition of steric stabilizing agents, such as polyvinylpyrrolidone (PVP) or polyvinyl alcohol (PVA) which avoids the agglomeration of the particles but at the same time limits the controlled variability of the size.

Department of Chemical Engineering and Biotechnology, Philippa Fawcett Drive, University of Cambridge, Cambridge, CB3 OAS, UK. E-mail: lt416@cam.ac.uk
In addition, these stabilising compounds may change the relevant surface properties of nanoparticles, such as biocompatibility or catalytic activity, having a detrimental effect on their final applications. ${ }^{11,12}$

In this context, microreactors have been presented as an alternative for the large scale reproducible production of nanoparticles. Importantly, the laminar flow regime characteristic of micro-devices provide a unique capability for the production of nanoparticles in the absence of steric stabilizing agents. In our previous work, ${ }^{13}$ we have demonstrated that narrow-sized silver nanoparticles can be synthesised via simple chemical reduction of silver nitrate with sodium borohydride without any additional stabilizing agents using helical microreactors. The coalescence and agglomeration of silver nanoparticles are minimized due to the laminar flow regime in the microreactor while the size distribution is narrowed by the controlled radial mixing promoted by the secondary flows (also called Dean vortices) generated in helical geometries. Despite the potential of this technology to continuously manufacture silver nanoparticles with small sizes $(<5.5 \mathrm{~nm})$ and narrow distributions, larger sizes present considerably broader size distributions, likely due to the strong nature of sodium borohydride as reducing agent. ${ }^{14}$

To overcome this limitation, in this paper, we report a robust, coiled flow inverter microreactor-based system for the synthesis of silver nanoparticles with tuneable and well defined sizes (between 5 and $10 \mathrm{~nm}$ ) via a seed-mediated growth method. Nucleation and growth stages take place in two separate reactors in series with different chemical 
environments where secondary nucleation is technically avoided during the growth step. In this way, the final size of the silver nanoparticles can be tuned by simply varying the concentration of silver precursor added in the second (growth) reactor. This approach provides an innovative approach to understand the size-activity relationship of nanoparticles in their application and this is illustrated here for the catalytic activity of silver nanoparticles in the reduction of 4-nitrophenol.

\section{Experimental procedures}

Reagents and chemicals used in this work, including silver nitrate solution $\left(\mathrm{AgNO}_{3}, 0.1 \mathrm{M}\right)$, trisodium citrate dihydrate $\left(\mathrm{Na}_{3} \mathrm{CA}, \geq 99 \%\right.$, FG), sodium borohydride powder $\left(\mathrm{NaBH}_{4}\right.$, ReagentPlus $\left.{ }^{\circledR}, 99 \%\right)$, sodium borohydride solution $\left(\mathrm{NaBH}_{4}\right.$, $12 \mathrm{wt} \%$ in $14 \mathrm{M} \mathrm{NaOH}$ ), 4-nitrophenol (4-NP, spectrophotometric grade), and bovine serum albumin (BSA) were all purchased from Sigma-Aldrich and used without further purification. Ultrapure water was obtained using an ELGA Maxima ultra-pure water system (18.2 $\mathrm{M} \Omega \mathrm{cm}$ resistivity).

\subsection{Synthesis of silver nanoparticles}

Silver nanoparticles were synthesised in two microreactors connected in series using a seed-mediated growth method in order to separate the nucleation and the growth stages. Fig. 1 shows a schematic of the reactor system which consists of two perfluoroalkoxy tubing (PFA, IDEX Health \& Science LLC) with a 0.03 inch inner diameter and 1/16 inch outer diameter coiled around a 3D-printed support (Form 1+ stereolithography printer from FormLabs). 3D printing technology was adopted here to provide a precise control of all the reactor's geometric parameters, such as helix diameter $(1 \mathrm{~cm})$, pitch distance $(1 / \pi \mathrm{cm})$, and tubing length.

In this system, silver nanoparticles with tuneable sizes were synthesised in two stages. In the first reactor, the synthesis of the seeds was carried out at $60^{\circ} \mathrm{C}$ using an aqueous solution (S1) containing freshly prepared $\mathrm{NaBH}_{4}(0.025 \mathrm{mM})$ as a primary reducing agent and $\mathrm{Na}_{3} \mathrm{CA}(0.35 \mathrm{mM})$ and a precursor aqueous solution (S2) containing $\mathrm{AgNO}_{3}$ (0.05 mM). Both solutions were introduced into reactor 1 using syringe pumps (Pump 11 Elite, Harvard Apparatus) with the volumetric flow rate for each pump fixed as $0.25 \mathrm{ml} \mathrm{min}^{-1}$, unless otherwise specified. The two steams were mixed in a $\mathrm{T}$ mixer (ETFE, $0.508 \mathrm{~mm}$ through hole, $2.9 \mu \mathrm{L}$ swept volume, IDEX Health \& Science LLC). Growth of the silver seeds took place in reactor 2 at $90{ }^{\circ} \mathrm{C}$ where an additional aqueous solution (S3) of metal precursor $\left(\mathrm{AgNO}_{3}\right.$, with the concentration of 0.5 , $1.0,1.5,1.75$, and $2 \mathrm{mM})$ and sodium acetate $\left(\mathrm{Na}_{3} \mathrm{CA}: \mathrm{AgNO}_{3}\right.$ ratio of 7) was introduced using a syringe pump and mixed with the seed solution from reactor 1 . The volumetric flow

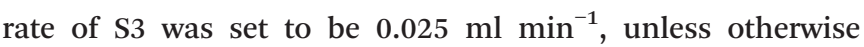
specified. The reaction temperatures were controlled using stirred water bath and IKA RCT basic stirrer hotplates equipped with an IKA ETS-D5 temperature controller (uncertainty of $\pm 0.1 \mathrm{~K})$. The reaction time was controlled by adjusting the total flow rate and tubular reactor length. The outlet of the reactor was introduced into an ice cold solution initially containing pure water to reduce the mobility and consequent agglomeration of the particles post-synthesis in the absence of capping ligands. Both the formation of seeds and their growth presented a high reproducibility.

\subsection{Reduction of 4-nitrophenol in aqueous solution}

The relationship of silver nanoparticle and their catalytic activity was evaluated using the reduction of 4-nitrophenol with $\mathrm{NaBH}_{4}$ as a model reaction. ${ }^{15}$ The reaction was carried out in $4.5 \mathrm{~mL}$ quartz cuvettes with a path length of $1 \mathrm{~cm}$. The total reaction volume was fixed as $3 \mathrm{~mL}$ with an initial 4-nitrophenol concentration of $3.3 \times 10^{-5} \mathrm{M}$ and $\mathrm{NaBH}_{4}$ concentration of $6.6 \times 10^{-2} \mathrm{M}$. The reaction was started by the addition of a certain amount of as-prepared $\mathrm{Ag}$ nanoparticles with different particle sizes at room temperature. Immediately after particles addition, time-dependent ultraviolet-visible (UV-vis) absorbance spectra were recorded at room

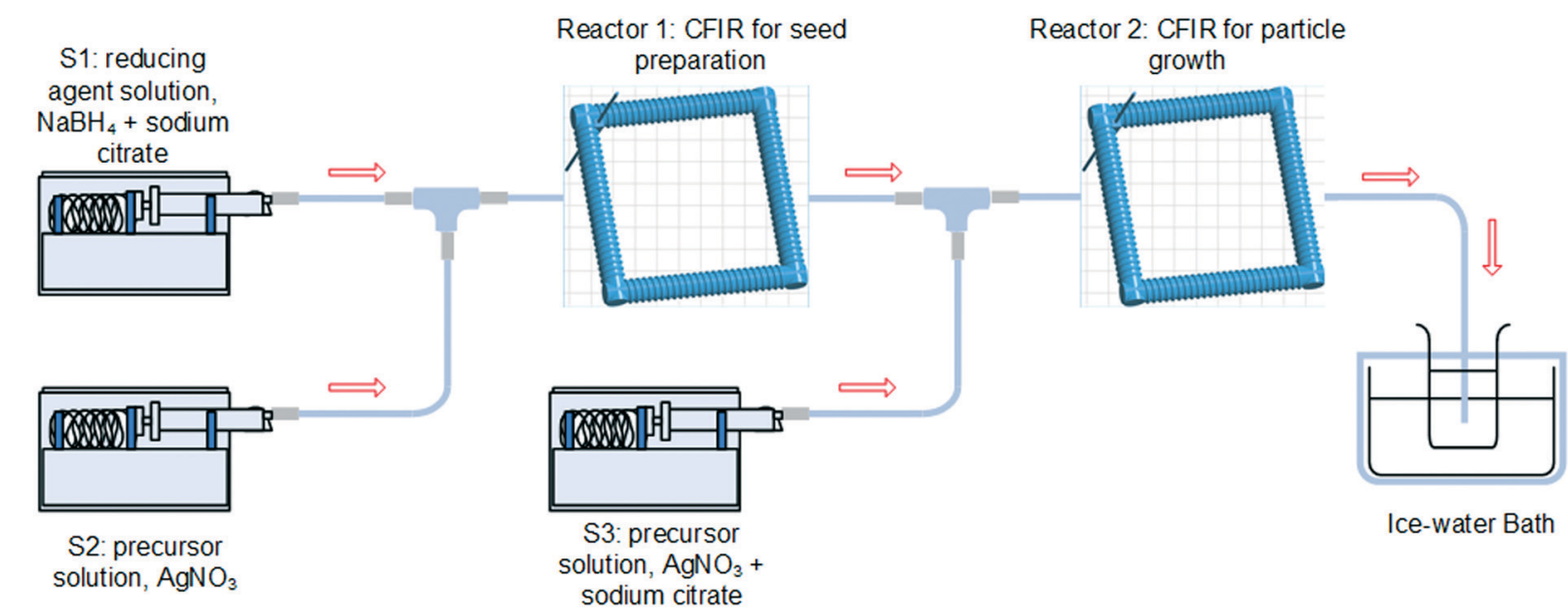

Fig. 1 Schematic diagram of the experimental setup. 
temperature. The background correction was done with deionized water as reference.

\subsection{Characterization of nanoparticles}

Ultraviolet-visible spectroscopy measurements were performed on an Agilent Cary 60 UV-vis spectrophotometer in the 300 to $800 \mathrm{~nm}$ wavelength range with a resolution of $1 \mathrm{~nm}$. Transmission electron microscopy (TEM) images were obtained using a FEI Tecnai 20 transmission electron microscope. Specimens for TEM analysis were prepared according to Michen et al.'s proto$\mathrm{col}^{16}$ to avoid post-synthesis agglomeration. In this method, 0.3 $\mathrm{g} \mathrm{ml}^{-1}$ BSA solution was mixed with the silver nanoparticle solution in a 1:1 ratio and the mixture was then kept in an icewater bath for at least 2 hours before preparing the TEM grid. A $5 \mu \mathrm{L}$ mixture droplet was then dripped onto a carbon coated copper grid and then naturally dried for over 2 hours. The TEM images were analysed using an image processing software, ImageJ, to obtain the area-equivalent diameter of the nanoparticles. The measurement uncertainty due to the image resolution is about $2 \%$.

\section{Results and discussion}

We have recently demonstrated how the characteristic laminar flow in microreactors enables the synthesis of metal nanoparticles (e.g. silver) in the absence of steric capping ligands. ${ }^{13}$ Three-dimensional reactor configurations promote the rotation of the fluid by controllable generation of gentle secondary flows leading to silver nanoparticles with tuneable sizes $\leq 5 \mathrm{~nm}$ and narrow size distributions $( \pm 0.8 \mathrm{~nm})$. The magnitude of such secondary flows, also called Lagrangian turbulence or Dean vortices, can be quantified by the dimensionless Dean number:

$$
D_{\mathrm{n}}=\sqrt{\frac{r}{R} \operatorname{Re}}
$$

(a)

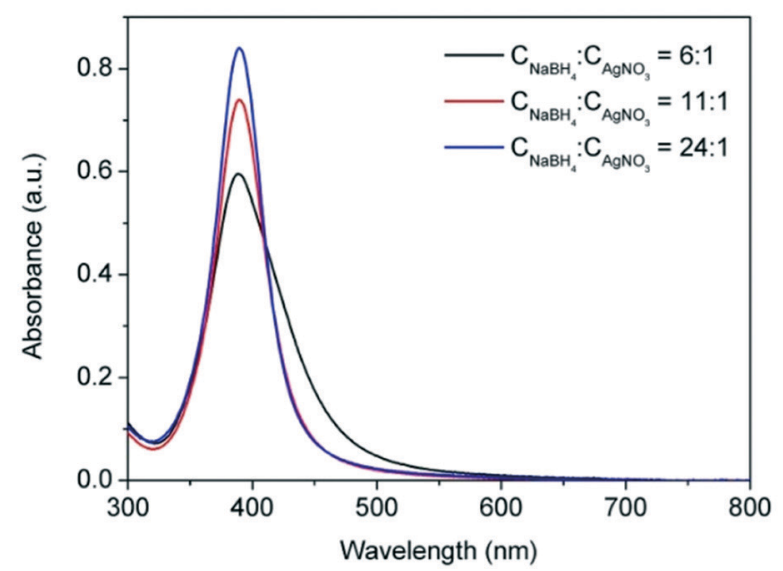

where $r$ is the inner radius of the tube, $R$ is the radius of the helix and Re is the Reynolds number. The Dean number shows a strong relationship not only with the size but also with the corresponding size distribution of the resulting particles. In this way, small $(<5 \mathrm{~nm})$ and narrow sized silver particles are generated at Dean numbers above 6 , while bigger sizes but also with considerable broader dispersities are obtained at Dean numbers below $6 .^{13}$

A first attempt to broaden the size span of narrowly dispersed nanoparticles was carried out by varying the concentrations of $\mathrm{AgNO}_{3}$ and reducing agent, $\mathrm{NaBH}_{4}$, in the reactor. The effect of concentration ratio of $\mathrm{NaBH}_{4}: \mathrm{AgNO}_{3}$ on silver nanoparticles size and size distribution was investigated by keeping constant the concentration of $\mathrm{AgNO}_{3}$ as $0.1 \mathrm{mM}$ and varying the concentration of $\mathrm{NaBH}_{4}$. From Fig. 2, it can be observed that increasing the $\mathrm{NaBH}_{4}: \mathrm{AgNO}_{3}$ molar ratio from $6: 1$ to $24: 1$ leads to sharper and higher absorbance peaks with FWHM values dropping from $69 \mathrm{~nm}$ to $45 \mathrm{~nm}$ while the absorbance increasing from 0.60 to 0.84 . This indicates that increasing the $\mathrm{NaBH}_{4}: \mathrm{AgNO}_{3}$ molar ratio leads to lower size polydispersity due to the faster nucleation process promoted by the higher $\mathrm{NaBH}_{4}$ concentration. However, no significant red or blue shifts of the absorbance peak $( \pm 1 \mathrm{~nm})$ were observed within the $\mathrm{NaBH}_{4}$ : $\mathrm{AgNO}_{3}$ molar ratio studied, indicating similar average nanoparticle sizes in all cases. In all cases, full conversion of silver precursor was achieved as illustrated in our previous studies of the effect of the length of reactor. ${ }^{17}$

In addition, the effect of silver precursor concentration on the silver nanoparticles size and size distribution was investigated by keeping the $\mathrm{NaBH}_{4}$ : $\mathrm{AgNO}_{3}$ molar ratio constant 11: 1, while varying the $\mathrm{AgNO}_{3}$ concentration between 0.05 and 2 $\mathrm{mM}$. It can be seen from Fig. 3 that increasing the concentration of $\mathrm{AgNO}_{3}$ within this range leads to a higher absorbance due to the higher concentration of silver nanoparticles formed. It is also interesting to observe that at higher concentrations, the ionic strength of the solution destabilizes the particles

(b)

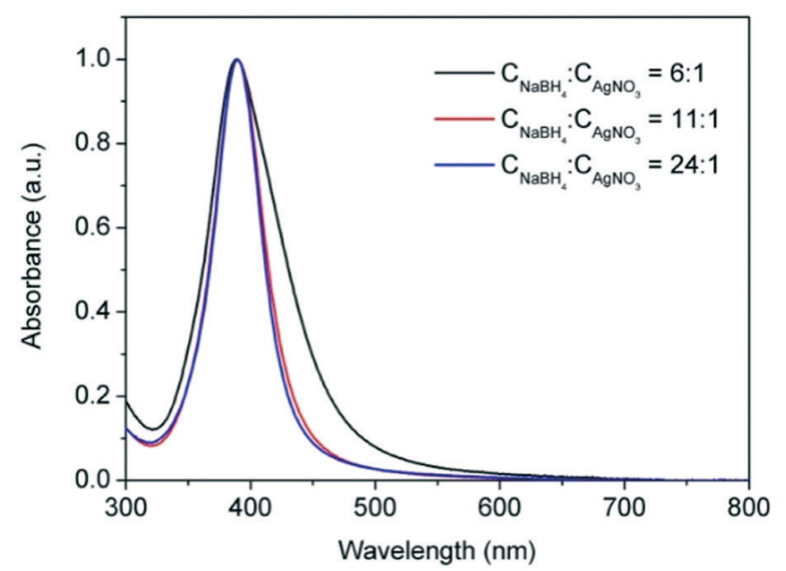

Fig. 2 (a) UV-vis absorbance spectra and (b) normalized absorbance spectra for Ag nanoparticles synthesized with different concentration ratio of $\mathrm{NaBH}_{4}: \mathrm{AgNO}_{3}$. SHR, helix diameter: $10 \mathrm{~mm}$, pitch distance: $1 / \pi \mathrm{cm}$, length: $1 \mathrm{~m}, 0.03$ " ID. The total flowrate is $0.5 \mathrm{~mL} \mathrm{~min}^{-1}$, residence time: $54 \mathrm{~s}$. 
causing an increase of FWHM values from $48 \mathrm{~nm}$ to $58 \mathrm{~nm}$ due to agglomeration taking place. In any case, again no significant red or blue shifts of the absorbance peaks $( \pm 1 \mathrm{~nm})$ were observed indicating lack of growth of the particles and similarity in average particle size obtained in all the cases.

Based on the experimental results above, one might reasonably draw the conclusion that simply varying the concentrations of $\mathrm{AgNO}_{3}$ and $\mathrm{NaBH}_{4}$ does not allow the control of the size of the silver particles due to the nature of $\mathrm{NaBH}_{4}$. As a strong reducing agent, nucleation dominates the process in the presence of $\mathrm{NaBH}_{4}$ which makes this system suitable for small nanoparticle $(<5 \mathrm{~nm})$ synthesis. While large silver particles could be synthesized using mild reducing agents, such as $\mathrm{Na}_{3}$ $\mathrm{CA}$, it is difficult to tune the size while keeping narrow size distributions due to the simultaneous nucleation and growth. ${ }^{18}$

Building upon these results, we have now developed an alternative strategy to continuously produce silver nanoparticles with a narrow size distribution in a wider range of sizes (from 5 to $10 \mathrm{~nm}$ ). Herein, we demonstrate a continuous seed-mediated growth system achieved by connecting two microreactors in series where controlled nucleation takes place in the first reactor followed by the seed growth in the second reactor. The success of this approach depends on the simultaneous compliance of a number of factors, mainly the formation of seeds with narrow size distributions and the use of different reducing agents in the seed and growth reactors to ensure the separation of both steps. The seed-mediated growth system has been previously reported in both flow and batch synthesis ${ }^{19}$ however, it is normally carried out in multiple steps in the presence of organic stabilising ligands while in this work, only citrate stabilised seeds are used.

Firstly, the final size distribution strongly depends on obtaining a narrow size distribution in the nucleation reactor 1 as well as ensuring continuous undisrupted laminar flow across the system to avoid random agglomeration of the particles. In order to produce seeds with the smallest possible poly- dispersity, coiled flow inverter reactors (CFIRs) were designed to enhance the formation of the Dean vortices in multiple directions across the reactor. A CFIR, depicted in Fig. 4a, consists of four straight helical modules where Dean vortices promote the rotation of the fluid. After each straight helix module, the coil direction is changed by a $90^{\circ}$ bend leading to a change in the direction of the centrifugal force and consequently the direction of the fluid rotation. Radial mixing is maximised by implementing equidistant right angle bends that change the direction of the centrifugal force, thus inducing new Dean vortices that drastically enhance radial mixing.

The synthesis of silver nanoparticles in coiled flow inverted reactors leads to smaller silver particles than the equivalent straight helical reactors (SHR) under the same conditions. As an example, Fig. 5 shows the particles formed with a $\mathrm{NaBH}_{4}: \mathrm{AgNO}_{3}$ molar ratio of 6 in a CFIR $(3.4 \pm 0.7$ $\mathrm{nm})$ compared to those formed in the straight helical reactor $(4.6 \pm 1.0 \mathrm{~nm})$ under the same conditions and residence time. It is important to mention that fouling of the PFA reactor was not observed even after running the synthesis consecutively for hours. However, fouling was observed in the ETFE T-mixer just after the first 20 minutes of reaction. This is the only point in the system where turbulent mixing takes place which can lead to heterogeneous nucleation in the mixer walls. The residence time of the solution in the T-mixer is below $1 \mathrm{~s}$ and this factor did not affect the reproducibility of the syntheses in both the SHR and the CFIR systems.

The residence time distributions in both the straight helical reactor and the coiled flow inverter reactor were calculated using computational fluid dynamics (CFD). For this, a discrete phase model (DPM) was employed where a tracer fluid represented by a large number of discrete massless particles was introduced into a fully developed flow followed by Lagrangian particle tracking analysis to obtain a histogram of the number of particles as a function of time. ${ }^{13}$ As shown in Fig. 4b, the CFIR presents not only a significant narrowing of (a)

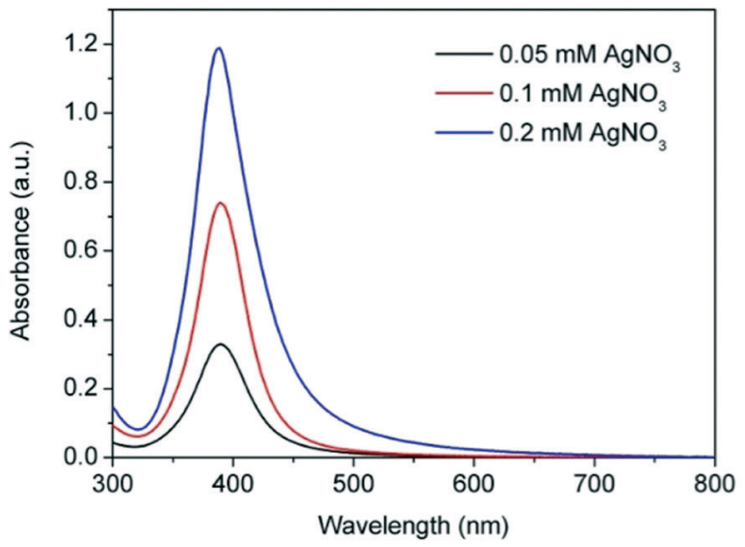

(b)

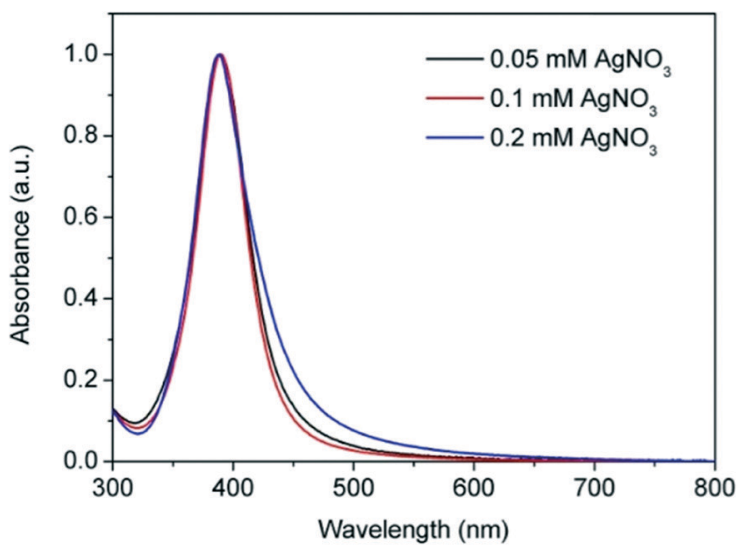

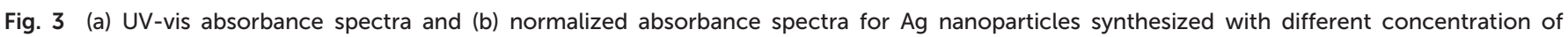

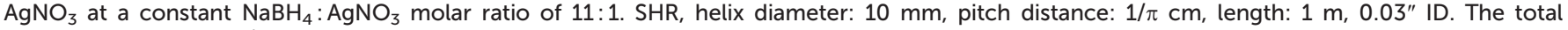
flowrate is $0.5 \mathrm{~mL} \mathrm{~min}^{-1}$, residence time: $54 \mathrm{~s}$. 
(a)

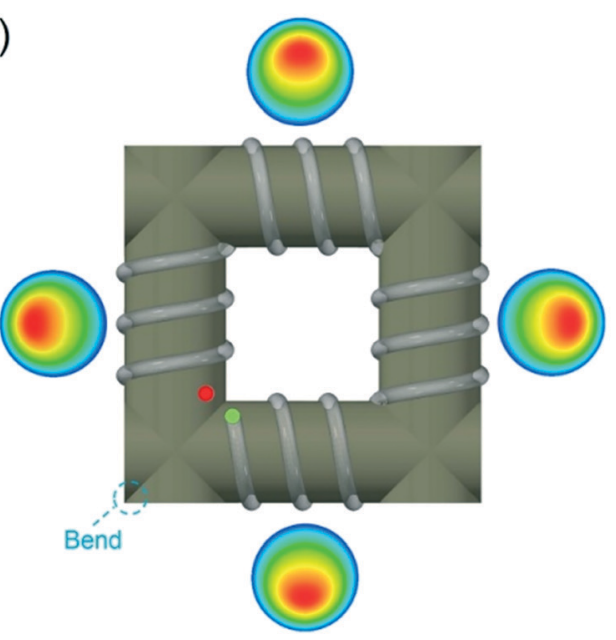

(b)

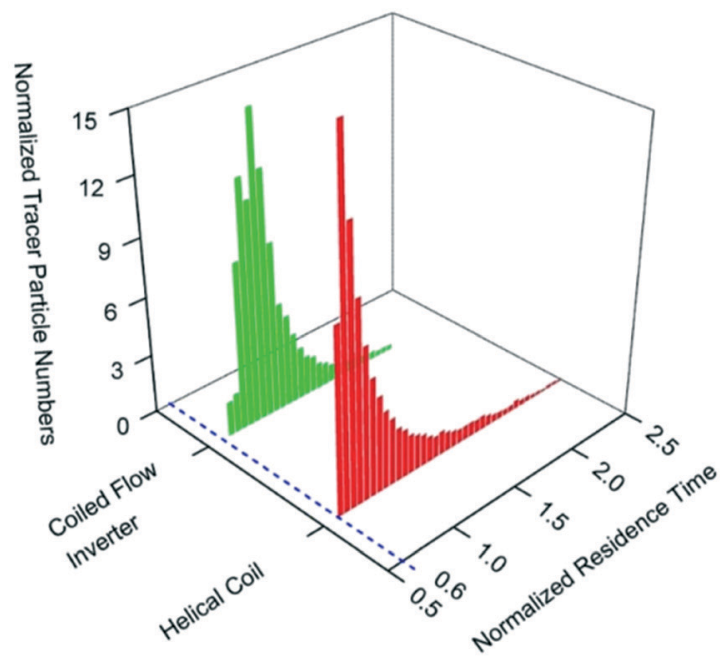

Fig. 4 (a) Illustration of coiled flow inverter reactor with 90 degree bends and the velocity profile in each of the sections. It can be observed that the maximum velocity is shifted towards the direction of the centrifugal force in each of the straight sections. Red and green dots represent the inlet and outlet points, respectively. (b) Comparison of the dimensionless residence time distribution in straight helical reactor and CFIR.
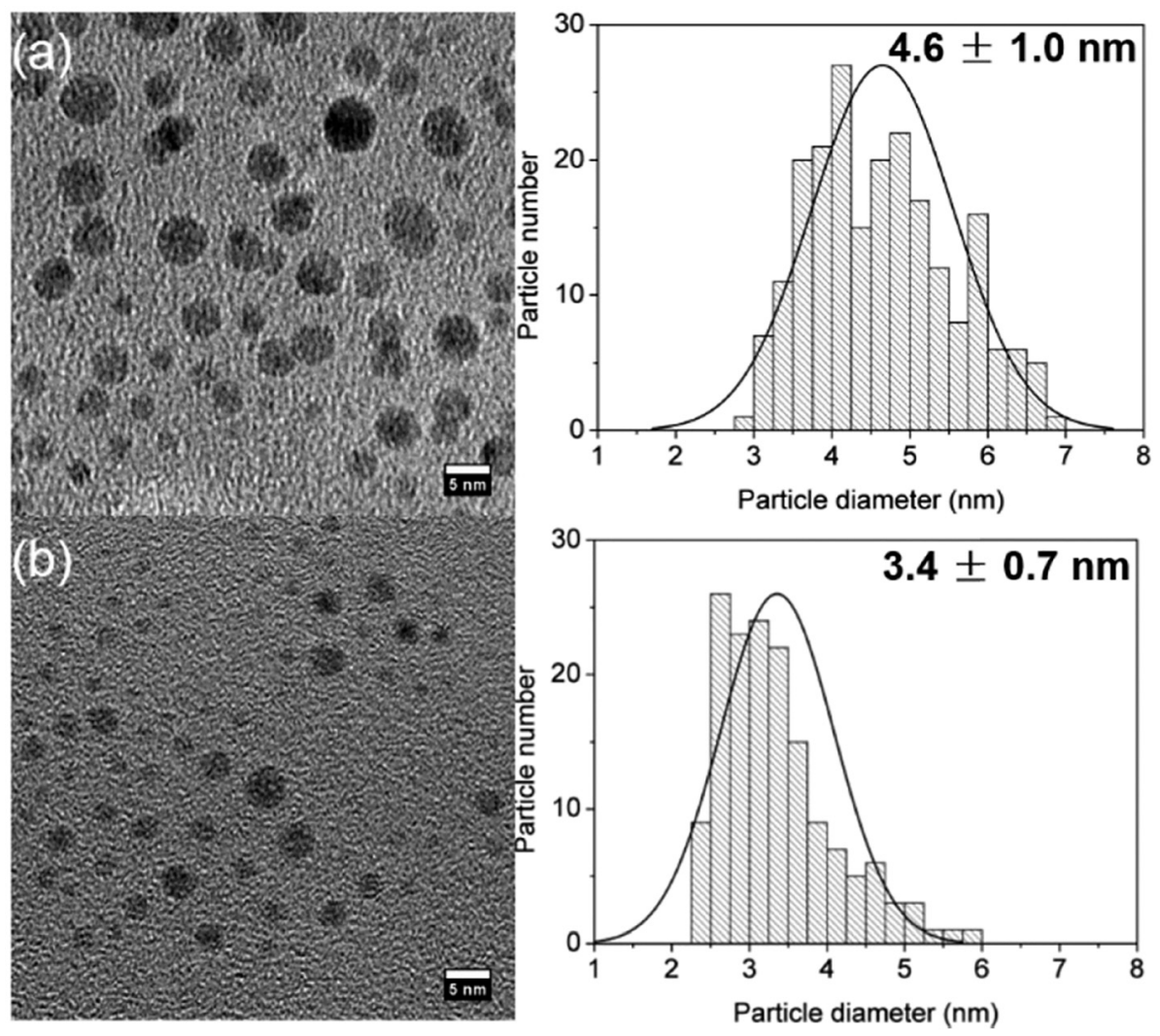

Fig. 5 Size and size distribution Ag nanoparticles from (a) SHR and (b) CFIR; helix diameter: $10 \mathrm{~mm}$, pitch distance: $1 / \pi \mathrm{cm}$, length: $1 \mathrm{~m}, 0.03^{\prime \prime}$ ID. $0.6 \mathrm{mM} \mathrm{NaBH}_{4}, 0.1 \mathrm{mM} \mathrm{AgNO}_{3}$, total flow rate: $0.7 \mathrm{ml} \mathrm{min}^{-1}, 60{ }^{\circ} \mathrm{C}$, residence time: $39 \mathrm{~s}$.

residence time distribution compared with the SHR under the same flow conditions but also a small delay for the appearance of the first tracking particles in the outlet of the reactor. Both aspects homogenise the residence time of the nanoparticles in the reactor, independently of the position of their formation in the cross section of the reactor, leading to the narrower size distributions as shown above.
In order to selectively grow these narrowly sized distributed seeds in reactor 2 , a drastic change in chemical environment needs to be ensured between the first and the second reactor to guarantee that no further nucleation takes place in the growth reactor 2 . It is well known that using strong reducing agents such as $\mathrm{NaBH}_{4}$ leads to quick nucleation, as we have shown above. While this is desired in the first 
reactor, the presence of $\mathrm{NaBH}_{4}$ would lead to secondary nucleation in reactor 2 . Thus, ideally, $\mathrm{NaBH}_{4}$ should be completely consumed or hydrolysed in the reactor 1 .

Full reduction of the silver precursor requires a stoichiometric $\mathrm{NaBH}_{4}$ to $\mathrm{AgNO}_{3}$ ratio of 1:8 under basic condition according to the following reaction:

$$
8 \mathrm{Ag}^{+}+\mathrm{BH}_{4}^{-}+8 \mathrm{OH}^{-} \rightarrow 8 \mathrm{Ag}+\mathrm{H}_{2} \mathrm{BO}_{3}{ }^{-}+5 \mathrm{H}_{2} \mathrm{O}
$$

however, the hydrolysis of $\mathrm{NaBH}_{4}$ is a competing reaction which results in the decrease of $\mathrm{NaBH}_{4}$ concentration in the system and the formation of scattered bubbles in the system. This hydrolysis reaction is greatly minimised under basic conditions as the ones studied herein.

$$
\mathrm{BH}_{4}^{-}+2 \mathrm{H}_{2} \mathrm{O} \rightarrow 2 \mathrm{BO}_{2}^{-}+4 \mathrm{H}_{2}
$$

The effect of $\mathrm{NaBH}_{4}: \mathrm{AgNO}_{3}$ molar ratio on the silver conversion and size distribution after reactor 1 was investigated by keeping the concentration of $\mathrm{AgNO}_{3}(0.05 \mathrm{mM})$ and the molar ratio of $\mathrm{NaBH}_{4}: \mathrm{NaOH}(1: 2.75)$ constant while varying the $\mathrm{NaBH}_{4}$ concentration. From Fig. 6, it can be observed that while almost full conversion is achieved at a $\mathrm{NaBH}_{4}: \mathrm{AgNO}_{3}$ ratio of $6: 1$ (by comparing the absorbance peak with the one in Fig. 2 at the same initial silver concentration), when the molar ratio of $\mathrm{NaBH}_{4}: \mathrm{AgNO}_{3}$ is decreased (e.g. $<6: 1$ ), the absorption of the resulting solution is relatively lower indicating a lower silver reduction conversion. In addition, low $\mathrm{NaBH}_{4}: \mathrm{AgNO}_{3}$ molar ratios also lead to very broad absorption peaks, representative of broad size distributions due to the role of $\mathrm{NaBH}_{4}$ as the electrostatic stabilizer in our system in the absence of additional capping agents. However, as mentioned above, the excess of $\mathrm{NaBH}_{4}$ would trigger secondary nucleation in reactor 2 .

An alternative, narrow particle size distribution and almost full $\mathrm{Ag}$ reduction can be obtained with low $\mathrm{NaBH}_{4}: \mathrm{AgNO}_{3}$ ratios by addition of $\mathrm{Na}_{3} \mathrm{CA}$ in reactor 1 . The presence of $\mathrm{Na}_{3} \mathrm{CA}$ enhances the reduction of $\mathrm{AgNO}_{3}$ by $\mathrm{NaBH}_{4}$ (requiring lower
$\mathrm{NaBH}_{4}: \mathrm{AgNO}_{3}$ concentration ratios) by releasing $\mathrm{OH}^{-}$ions (reaction 4 ) increasing the reduction reaction kinetics (reaction 2):

$$
\mathrm{C}_{6} \mathrm{H}_{5} \mathrm{O}_{7}{ }^{3-}+\mathrm{H}_{2} \mathrm{O} \leftrightarrow \mathrm{C}_{6} \mathrm{H}_{6} \mathrm{O}_{7}{ }^{2-}+\mathrm{OH}^{-}
$$

indeed, the $\mathrm{Ag}$ reduction conversion is greatly increased in the presence of $\mathrm{Na}_{3} \mathrm{CA}$ as shown by the increase in absorbance in Fig. 7 respect to the same reaction in its absence for a given low $\mathrm{NaBH}_{4}: \mathrm{AgNO}_{3}$ ratio $(0.5: 1)$. It is also important to mention that under this reaction temperature, $\mathrm{Na}_{3} \mathrm{CA}$ cannot reduce $\mathrm{AgNO}_{3}$ in the absence of $\mathrm{NaBH}_{4}$ (Fig. 7).

In addition, $\mathrm{Na}_{3} \mathrm{CA}$ is widely used as a stabilizer for the synthesis of noble metal colloids with accessible surfaces due to the weak interaction of $\mathrm{Na}_{3} \mathrm{CA}$ molecules with metal surfaces. ${ }^{20}$ In this way, its presence in reactor 1 , offers an alternative electrostatic stabilisation of the seed particles leading to narrow size distribution $(\mathrm{FWHM}=43 \mathrm{~nm})$ at low $\mathrm{NaBH}_{4}$ : $\mathrm{AgNO}_{3}$ molar ratios $(0.5: 1)$.

To ensure the complete hydrolysis of any excess of $\mathrm{NaBH}_{4}$ remaining in the system, the length of the reactor 1 (i.e. residence time) was increased from 130 to $320 \mathrm{~cm}$, increasing the residence time from 71 to $175 \mathrm{~s}$. Negligible differences in size and size distribution were observed in both cases.

The silver seeds formed in reactor $1(5.4 \pm 1.1 \mathrm{~nm}$, see particle sizing below) were then introduced into the reactor 2 for their controlled growth. For this, additional $\mathrm{AgNO}_{3}$ precursor was introduced in addition to $\mathrm{Na}_{3} \mathrm{CA}$ as supplementary reducing agent. A mild reducing agent, such as $\mathrm{Na}_{3} \mathrm{CA}$, is favourable to ensure only growth of the silver seeds. Under these conditions, the surface of the silver particles act as a self-catalysts, significantly decreasing the energy barrier for the reduction of $\mathrm{Ag}^{+}$into $\mathrm{Ag}^{0}$. At the same time, $\mathrm{Na}_{3} \mathrm{CA}$ is not able to reduce $\mathrm{Ag}^{+}$in the bulk solution and form nuclei as shown before, leading to a separation of the nucleation in reactor 1 and growth in reactor 2 .

Addition of $\mathrm{Na}_{3} \mathrm{CA}$ and additional silver precursor in reactor 2 leads to a shift in the absorbance peak of the resulting (a)

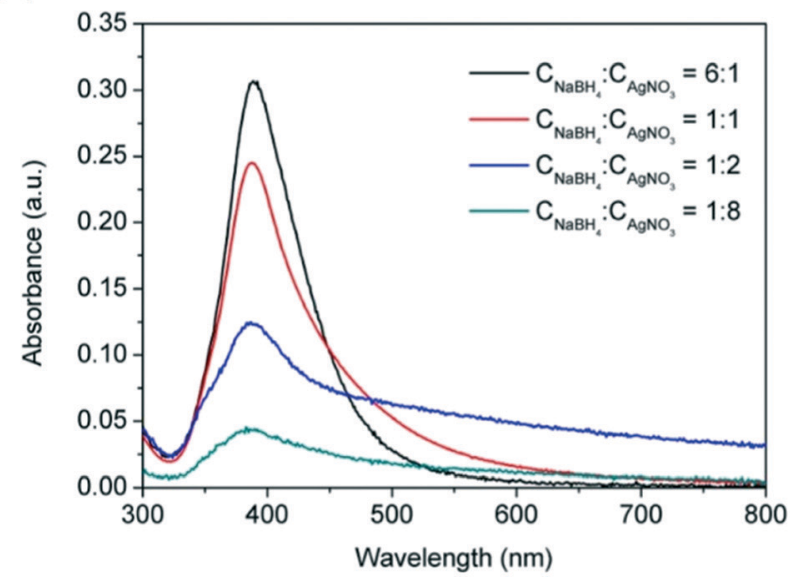

(b)

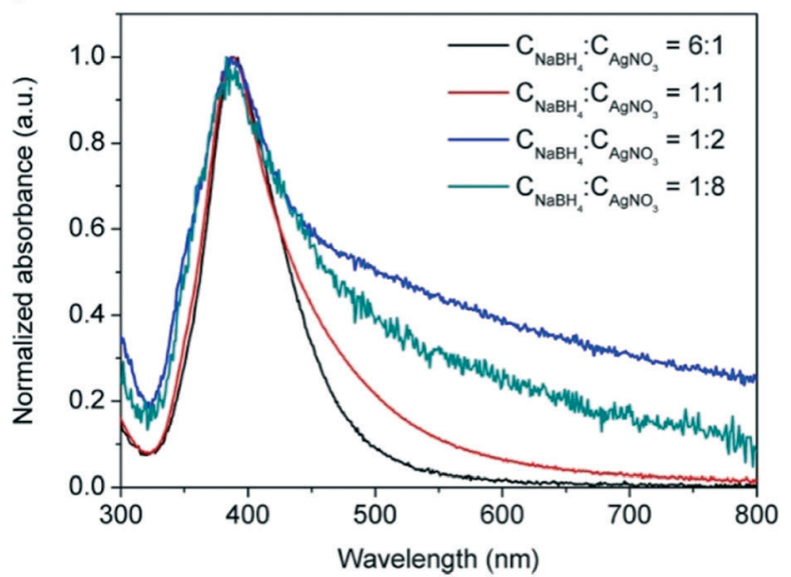

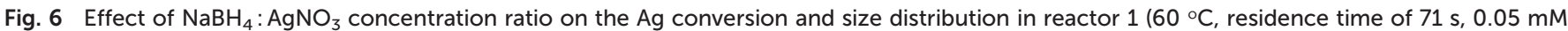
$\left.\mathrm{AgNO}_{3},\left[\mathrm{NaBH}_{4}\right]:[\mathrm{NaOH}]=1: 2.75\right)$ : (a) UV-vis spectra and (b) normalised UV-vis spectra. 


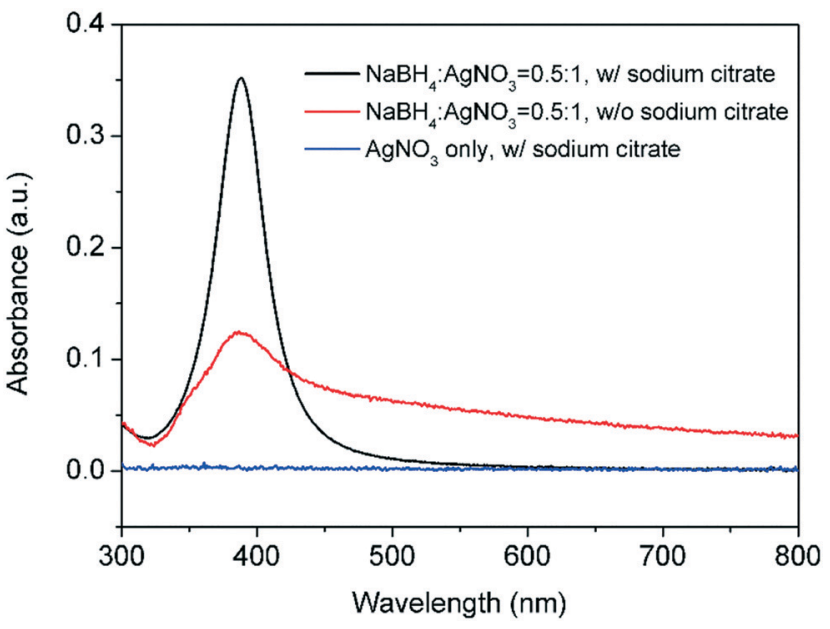

Fig. 7 Effect of the presence of sodium citrate on the silver conversion (proportional to absorption) and size distribution: $0.05 \mathrm{mM}$ $\mathrm{AgNO}_{3}, 0.025 \mathrm{mM} \mathrm{NaBH}_{4}$, and $0.35 \mathrm{mM} \mathrm{Na}_{3} \mathrm{CA}, 60{ }^{\circ} \mathrm{C}$, residence time of $71 \mathrm{~s}, \mathrm{CFIR}$.

solution, characteristic of bigger particles, compared to the spectrum of the initial seeds as shown in Fig. 8. Contrary, the addition of $\mathrm{NaBH}_{4}$ as reducing agent in reactor 2 leads to simultaneous nucleation and growth, broadening greatly the final size distribution as suggested by the broad absorbance peak.

Based on these results, the degree in growth in the second reactor, and consequently the resulting $\mathrm{Ag}$ particle size was tuned by simply varying the inlet concentration of silver precursor in reactor 2 (while keeping the $\mathrm{Na}_{3} \mathrm{CA}: \mathrm{AgNO}_{3}$ molar ratio constant and equal to 7). $\mathrm{AgNO}_{3}$ inlet concentrations of $0.5 \mathrm{mM}, 1.0 \mathrm{mM}, 1.5 \mathrm{mM}, 1.75 \mathrm{mM}$, and $2.0 \mathrm{mM}$ were studied and labelled as AG- $X$ mM, where $X$ represents the inlet $\mathrm{AgNO}_{3}$ concentration in the second reactor. Fig. 9 clearly shows that the absorbance not only increases as the inlet concentration of silver in the second reactor increases, but also a clear red shift was observed indicating the formation of larger particles. Meanwhile, the polydispersity seems to slightly increase judged by the increase of FWHM values from $47 \mathrm{~nm}$ to $59 \mathrm{~nm}$ at silver concentrations of $0.5 \mathrm{mM}$ and $2 \mathrm{mM}$ respectively. In addition, as the inlet concentration of silver in the second reactor increases, a small shoulder at 350 $\mathrm{nm}$ appears. The origin of this phenomenon is still under discussion in the literature. Huang et $a l^{21}$ and Lee et al. ${ }^{22}$ claimed that it could be related to octupolar plasmon modes, however, Conde-González et al. ${ }^{23}$ related to the presence of small nanoparticles.

The silver particles present a good stability due to the presence of citrate. In order to confirm the control growth of the particles, accurate average particle size and size distribution were determined by TEM measurements. As shown in Fig. 10, the size of seed particles after reactor 1 was $5.4 \pm 1.1$ $\mathrm{nm}$. Increasing the inlet concentration of silver precursor in reactor 2 leads to a control increase of particle sizes, keeping similar low polydispersity values (within $15-20 \%$ ) in agreement with the UV-vis spectroscopy data. AG-0.5 mM, AG-1

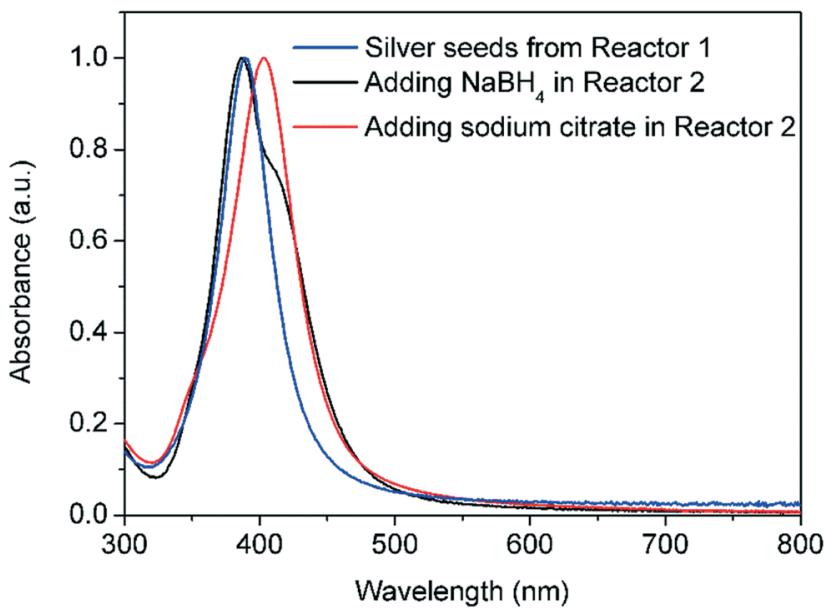

Fig. 8 Normalized UV-vis spectra of silver seeds synthesized in reactor 1 (CFIR; helix diameter: $10 \mathrm{~mm}$, pitch distance: $1 / \pi \mathrm{cm}$, length: 3.2 $\mathrm{m}, 0.03$ " ID, residence time: $175 \mathrm{~s}, 0.05 \mathrm{mM} \mathrm{AgNO}_{3}, 0.025 \mathrm{mM} \mathrm{NaBH}_{4}$, and $0.35 \mathrm{mM} \mathrm{Na}_{3} \mathrm{CA}, 60^{\circ} \mathrm{C}$ ) and after growth in reactor 2 (CFIR; helix diameter: $10 \mathrm{~mm}$, pitch distance: $1 / \pi \mathrm{cm}$, length: $3.2 \mathrm{~m}, 0.03^{\prime \prime} I D$, residence time: $167,14 \mathrm{mM}$ reducing agents and $2 \mathrm{mM} \mathrm{AgNO}_{3}, 90^{\circ} \mathrm{C}$ ).

mM, AG-1.5 mM, AG-1.75 mM, and AG-2 mM present $6.5 \pm$ $1.2 \mathrm{~nm}, 6.8 \pm 1.2 \mathrm{~nm}, 7.7 \pm 1.4 \mathrm{~nm}, 8.0 \pm 1.5 \mathrm{~nm}$ and $9.3 \pm$ $1.8 \mathrm{~nm}$, respectively, demonstrating a good size control in the range of 5 to $10 \mathrm{~nm}$.

This novel synthetic approach of metal nanoparticles with tuneable sizes will provide fundamental understanding of the effect of metal nanoparticles size on catalytic activity in the absence of capping ligands which are known to obscure these types of studies. ${ }^{24}$ The reduction potential is significantly different for metal nanoparticles of varying sizes in comparison to bulk metals, since the Fermi potential of nanoparticles

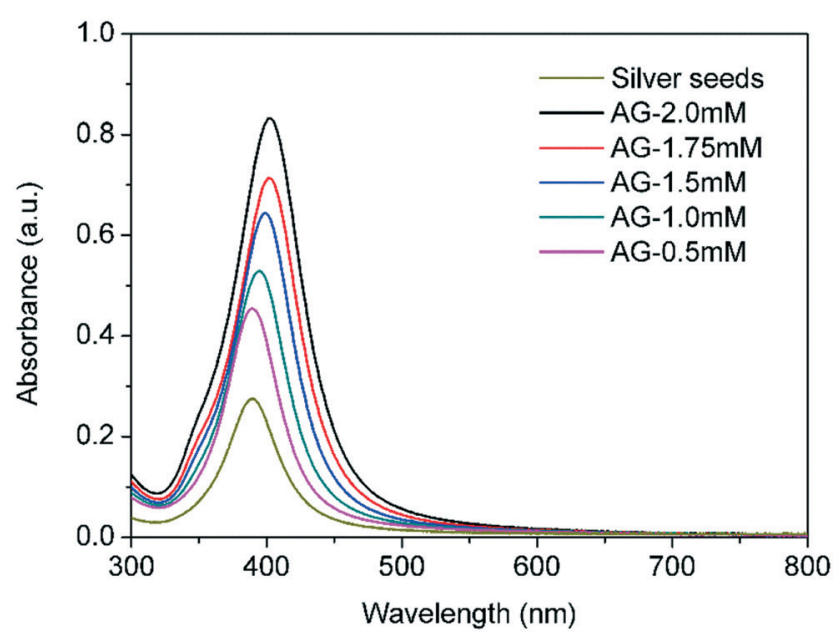

Fig. 9 UV-vis spectra for Ag nanoparticle solutions after the growth reactor 2 as a function of inlet $\mathrm{AgNO}_{3}$ concentration in the second reactor. Reactor 1: CFIR; helix diameter: $10 \mathrm{~mm}$, pitch distance: $1 / \pi$ $\mathrm{cm}$, length: $3.2 \mathrm{~m}, 0.03^{\prime \prime} \mathrm{ID}$, residence time: $175 \mathrm{~s}, 0.05 \mathrm{mM} \mathrm{AgNO}$, $0.025 \mathrm{mM} \mathrm{NaBH}$, and $0.35 \mathrm{mM} \mathrm{Na}{ }_{3} \mathrm{CA}, 60{ }^{\circ} \mathrm{C}$; reactor 2: $\left[\mathrm{Na}_{3} \mathrm{CA}\right]:\left[\mathrm{AgNO}_{3}\right]=7,90{ }^{\circ} \mathrm{C}, \mathrm{CFIR}$; helix diameter: $10 \mathrm{~mm}$, pitch distance: $1 / \pi \mathrm{cm}$, length: $3.2 \mathrm{~m}, 0.03^{\prime \prime} I D$, residence time: $167 \mathrm{~s}$. 

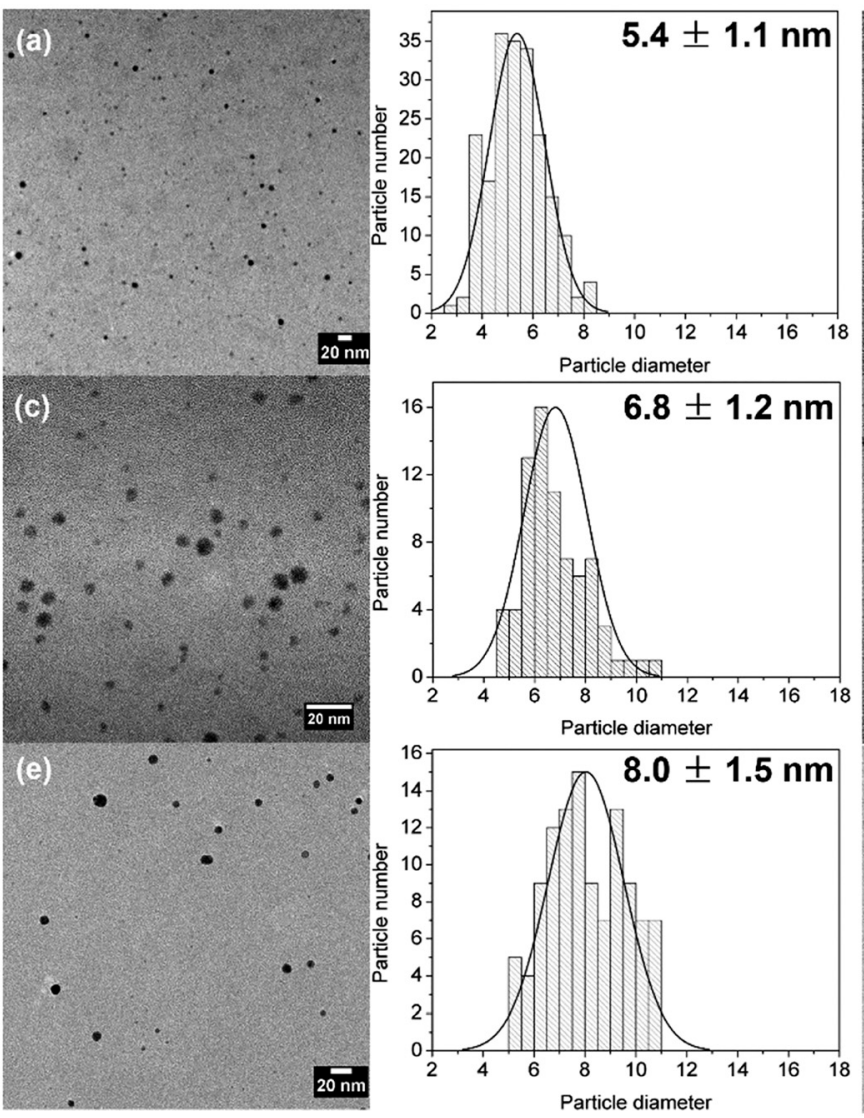

Fig. 10 TEM and particle size distribution of (a) seed particles, (b) AG-0.5 mM particles, (c) AG-1 mM particles, (d) AG-1.5 mM particles, (e) AG-1.75 mM particles and (f) AG-2 mM particles. Reaction conditions as in Fig. 9.

becomes more negative. ${ }^{25}$ To illustrate this, the reduction of 4-nitrophenol reaction was used herein as a case study (Fig. 11). This reaction is widely used in the literature because it allows for a straightforward assessment of the catalytic activity using the kinetic parameters extracted from the real-time UV-vis monitoring of an aqueous solution.

The absorption peak of the initial 4-NP aqueous solution underwent a red shift from $317 \mathrm{~nm}$ to $400 \mathrm{~nm}$ by addition of $\mathrm{NaBH}_{4}$. In the absence of a catalyst, the absorbance peak of the 4-NP anion at $400 \mathrm{~nm}$ was constant and stable. Upon the addition of the silver nanoparticles $\left(2.24 \times 10^{-5} \mathrm{~g} \mathrm{~L}^{-1}\right)$ previously synthesised without any intermediate purification or separation steps, the absorbance peak at $400 \mathrm{~nm}$ significantly decreased with time and a new peak at $300 \mathrm{~nm}$ corresponding to 4-aminophenol (4-AP) gradually developed. A typical
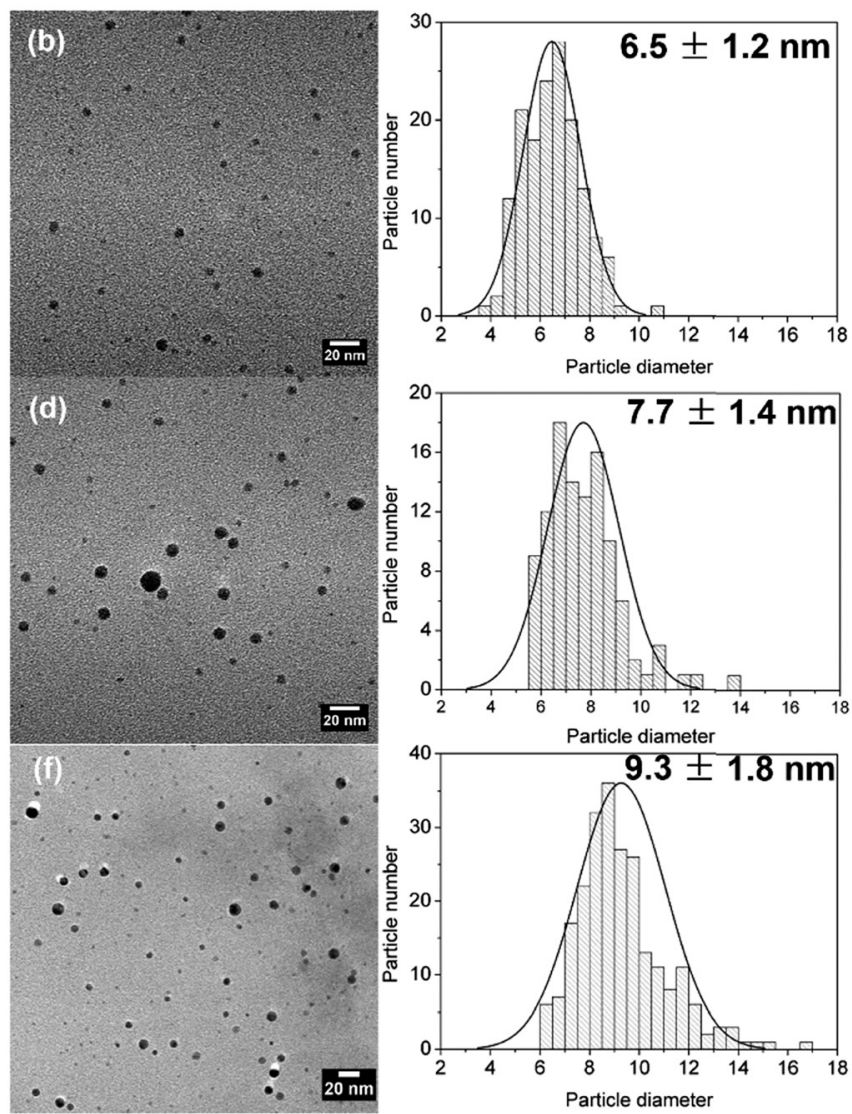
(a)

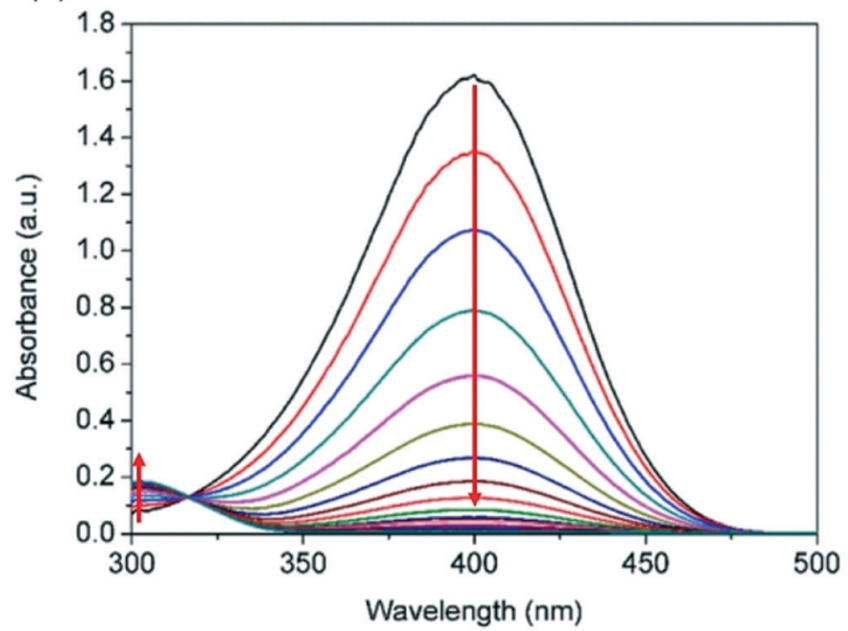

(b)

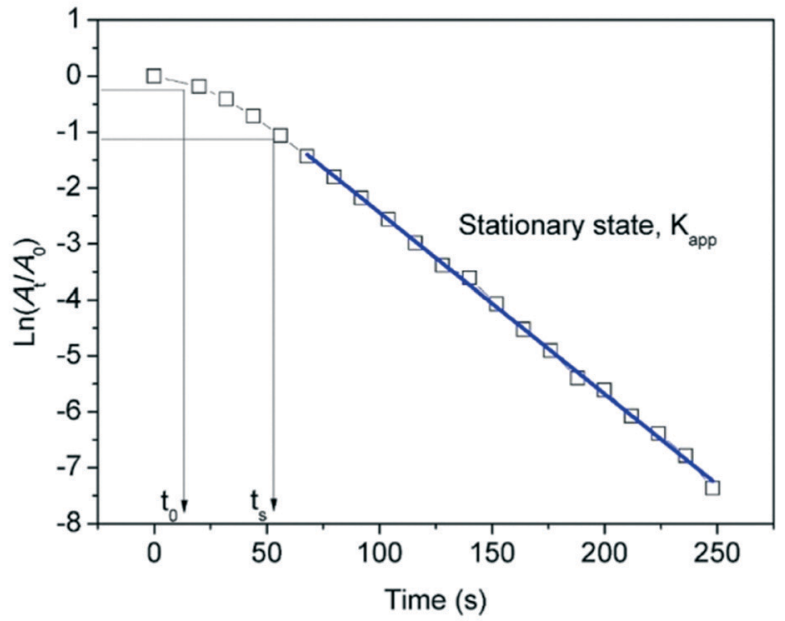

Fig. 12 Reduction of 4-nitrophenol by sodium borohydride by $2.24 \times 10^{-5} \mathrm{~g} \mathrm{~L}^{-1}$ silver nanoparticles. (a) UV-vis absorption spectra of the solution as a function of time. (b) Kinetic analysis of the system after the induction period.

where $C_{\mathrm{A}}$ is the concentration of 4-NP, and $K_{\text {app }}$ is the apparent rate constant in $\mathrm{s}^{-1}$.

The time dependence of the absorbance of 4-nitrophenolate ions at $400 \mathrm{~nm}$ is characterized by an induction period $t_{0}$ which is the time interval required for the level of dissolved oxygen to fall below a critical value, ${ }^{28}$ wherein the absorbance is constant, followed by a linear decrease as shown in Fig. 12b. As the absorbance of the solution is proportional to the 4-NP concentration (according to Beer Lambert law), simple derivation of eqn 5 leads to a linear correlation between the initial absorbance $\left(A_{0}\right)$, the absorbance at a given time $\left(A_{t}\right)$ and the apparent rate constant $\left(K_{\text {app }}\right)$ :

$$
-K_{\text {app }} t=\ln \frac{A_{t}}{A_{0}}=\ln \frac{C_{t}}{C_{0}}
$$

where $C_{0}$ is the initial concentration of the 4-nitrophenolate before silver nanoparticles are added and $C_{t}$ is the 4-NP concentration at a given time $(t)$. A standard typical fitting is shown in Fig. 12b where the induction period is disregarded.

A similar kinetic study was carried out using silver nanoparticles with different sizes (between 5 and $10 \mathrm{~nm}$ ) as synthesised above. From Fig. 13, it can be observed that the catalytic activity of silver nanoparticles does not increase with decreasing size. Instead an optimum particle size $6.5 \pm 1.2 \mathrm{~nm}$ is observed within the studied size range. ${ }^{15}$ Further stabilisation of the particles, e.g. by supporting them in carbon or oxide materials would be necessary to ensure their recyclability, however, this study clearly illustrates the potential of this novel manufacturing technology to provide unique and clear understanding of catalytic activity-size relationships. ${ }^{29}$

\section{Conclusions}

A novel route for the synthesis of silver nanoparticles with tuneable sizes $(5-10 \mathrm{~nm})$ in the absence of steric stabilising

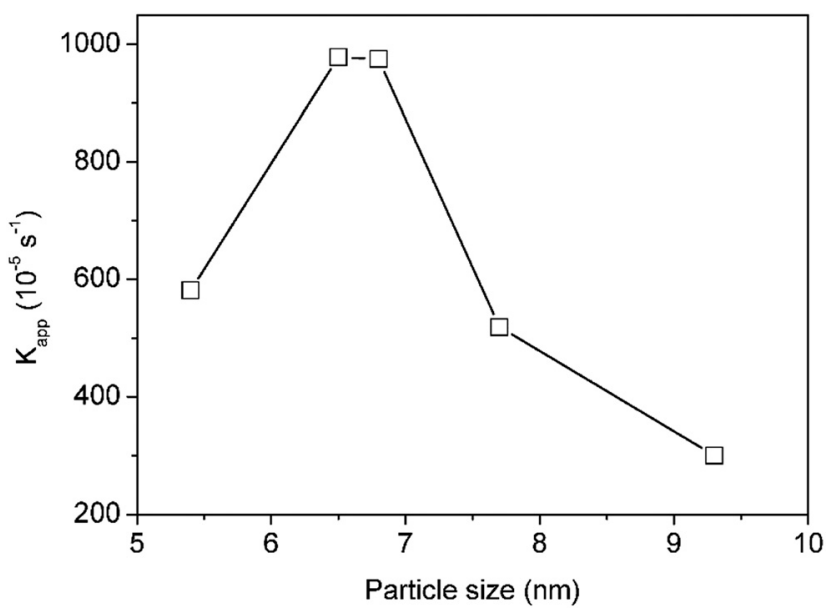

Fig. 13 Relationship between particle size and catalytic activity. Reaction conditions: $3.3 \times 10^{-5} \mathrm{M} 4-\mathrm{NP}, 6.6 \times 10^{-2} \mathrm{M} \mathrm{NaBH}_{4}$ and $2.24 \times$ $10^{-5} \mathrm{~g} \mathrm{~L}^{-1}$ silver nanoparticles at room temperature.

ligands is presented here where two coiled flow inverter reactors are connected in in series for the spatial and temposeparation of the nucleation and growth steps. This approach allows rapid changes of the chemical environment in both reactors with the use of strong reducing agents to ensure uniform seeds generation in the first reactor followed by milder reducing agents to avoid secondary nucleation in the growth reactor. In this way, the particle size can be tuned by simply varying the inlet concentration of silver precursor in the growth reactor while keeping a narrow size distribution. This approach presents a transformative route to study the real relationship between metal particle sizes in a number of applications without the influence of steric capping agents. This new capability is illustrated herein to evaluate the effect of silver particle size in their catalytic reduction activity and can be easily extrapolated to other metals and catalytic reactions, opening up a new avenue for catalysis understanding, development and design. 


\section{Conflicts of interest}

There are no conflicts to declare.

\section{Acknowledgements}

LTM would like to acknowledge the UK Engineering and Physical Science Research Council for her Fellowship award (grant number EP/L020432/2).

\section{References}

1 S. R. Wang, J. Zhang, J. Q. Jiang, R. Liu, B. L. Zhu, M. J. Xu, Y. Wang, J. L. Cao, M. Y. Li, Z. Y. Yuan, S. M. Zhang, W. P. Huang and S. H. Wu, Microporous Mesoporous Mater., 2009, 123(1-3), 349-353.

2 M.-C. Daniel and D. Astruc, Chem. Rev., 2004, 104(1), 293-346.

3 F. C. Walsh, D. V. Bavykin, L. Torrente-Murciano, A. A. Lapkin and B. A. Cressey, Trans. Inst. Met. Finish., 2006, 84(6), 293-299.

4 G. A. Martínez-Castañón, N. Niño-Martínez, F. MartínezGutierrez, J. R. Martínez-Mendoza and F. Ruiz, J. Nanopart. Res., 2008, 10(8), 1343-1348.

5 N. Lopez, T. V. W. Janssens, B. S. Clausen, Y. Xu, M. Mavrikakis, T. Bligaard and J. K. Nørskov, J. Catal., 2004, 223(1), 232-235.

6 L. Torrente-Murciano, T. Villager and D. Chadwick, ChemCatChem, 2015, 7(6), 925-927.

7 L. Torrente-Murciano, Q. He, G. J. Hutchings, C. J. Kiely and D. Chadwick, ChemCatChem, 2014, 6(9), 2531-2534.

8 M. Rafique, I. Sadaf, M. S. Rafique and M. B. Tahir, Artif. Cells, Nanomed., Biotechnol., 2017, 45(7), 1272-1291.

9 X.-Y. Dong, Z.-W. Gao, K.-F. Yang, W.-Q. Zhang and L.-W. Xu, Catal. Sci. Technol., 2015, 5(5), 2554-2574.

10 M. Wuithschick, B. Paul, R. Bienert, A. Sarfraz, U. Vainio, M. Sztucki, R. Kraehnert, P. Strasser, K. Rademann, F. Emmerling and J. Polte, Chem. Mater., 2013, 25(23), 4679-4689.

11 R. Ghosh Chaudhuri and S. Paria, Chem. Rev., 2012, 112(4), 2373-2433.
12 N. Jain, A. Bhargava, M. Rathi, R. V. Dilip and J. Panwar, PLoS One, 2015, 10(7), e0134337.

13 K.-J. Wu, G. M. De Varine Bohan and L. Torrente-Murciano, React. Chem. Eng., 2017, 2(2), 116-128.

14 S. Agnihotri, S. Mukherji and S. Mukherji, RSC Adv., 2014, 4(8), 3974-3983.

15 C. Kästner and A. F. Thünemann, Langmuir, 2016, 32(29), 7383-7391.

16 B. Michen, C. Geers, D. Vanhecke, C. Endes, B. RothenRutishauser, S. Balog and A. Petri-Fink, Sci. Rep., 2015, 5, 9793.

17 K. J. Wu, G. M. D. Bohan and L. Torrente-Murciano, React. Chem. Eng., 2017, 2(2), 116-128.

18 A. Pyatenko, M. Yamaguchi and M. Suzuki, J. Phys. Chem. C, 2007, 111(22), 7910-7917.

19 R. L. Zong, X. L. Wang, S. K. Shi and Y. F. Zhu, Phys. Chem. Chem. Phys., 2014, 16(9), 4236-4241.

20 N. G. Bastús, F. Merkoçi, J. Piella and V. Puntes, Chem. Mater., 2014, 26(9), 2836-2846.

21 Y. Huang, A. R. Ferhan and D.-H. Kim, Nanoscale, 2013, 5(17), 7772-7775.

22 Y. H. Lee, H. Chen, Q.-H. Xu and J. Wang, J. Phys. Chem. C, 2011, 115(16), 7997-8004.

23 J. E. Conde-González, E. M. Peña-Méndez, S. Rybáková, J. Pasán, C. Ruiz-Pérez and J. Havel, Chemosphere, 2016, 150, 659-666.

24 W. Huang, Q. Hua and T. Cao, Catal. Lett., 2014, 144(8), 1355-1369.

25 J. Noh and R. Meijboom, Reduction of 4-Nitrophenol as a Model Reaction for Nanocatalysis, in Application of Nanotechnology in Water Research, John Wiley \& Sons, Inc., 2014, pp. 333-405.

26 Z. Jin, M. Xiao, Z. Bao, P. Wang and J. Wang, Angew. Chem., Int. Ed., 2012, 51(26), 6406-6410.

27 S. Wunder, F. Polzer, Y. Lu, Y. Mei and M. Ballauff, J. Phys. Chem. C, 2010, 114(19), 8814-8820.

28 E. Menumerov, R. A. Hughes and S. Neretina, Nano Lett., 2016, 16(12), 7791-7797.

29 T. García, S. Agouram, A. Dejoz, J. F. Sánchez-Royo, L. Torrente-Murciano and B. Solsona, Catal. Today, 2015, 248(0), 48-57. 